\title{
Front Matter: Volume 10330
}

, "Front Matter: Volume 10330," Proc. SPIE 10330, Modeling Aspects in Optical Metrology VI, 1033001 (13 July 2017); doi: 10.1117/12.2282906

SPIE. Event: SPIE Optical Metrology, 2017, Munich, Germany 


\title{
PROCEEDINGS OF SPIE
}

\section{Modeling Aspects in Optical Metrology VI}

\author{
Bernd Bodermann \\ Karsten Frenner \\ Richard M. Silver \\ Editors
}

\section{6-28 June 2017 \\ Munich, Germany}

Sponsored by

SPIE

Cooperating Organisations

European Optical Society

German Scientific Laser Society (Wissenschaftliche Gesellschaft

Lasertechnik e.V.)

Published by

SPIE 
The papers in this volume were part of the technical conference cited on the cover and title page. Papers were selected and subject to review by the editors and conference program committee. Some conference presentations may not be available for publication. Additional papers and presentation recordings may be available online in the SPIE Digital Library at SPIEDigitallibrary.org.

The papers reflect the work and thoughts of the authors and are published herein as submitted. The publisher is not responsible for the validity of the information or for any outcomes resulting from reliance thereon.

Please use the following format to cite material from this book:

Author(s), "Title of Paper," in Modeling Aspects in Optical Metrology VI, edited by Bernd Bodermann, Karsten Frenner, Richard M. Silver, Proceedings of SPIE Vol. 10330 (SPIE, Bellingham, WA, 2017) Seven-digit Article CID Number.

ISSN: 0277-786X

ISSN: 1996-756X (electronic)

ISBN: 9781510611054

ISBN: 9781510611061

Published by

SPIE

P.O. Box 10, Bellingham, Washington 98227-0010 USA

Telephone +1 3606763290 (Pacific Time) · Fax +1 3606471445

SPIE.org

Copyright (c) 2017, Society of Photo-Optical Instrumentation Engineers.

Copying of material in this book for internal or personal use, or for the internal or personal use of specific clients, beyond the fair use provisions granted by the U.S. Copyright Law is authorized by SPIE subject to payment of copying fees. The Transactional Reporting Service base fee for this volume is $\$ 18.00$ per article (or portion thereof), which should be paid directly to the Copyright Clearance Center (CCC), 222 Rosewood Drive, Danvers, MA 01923. Payment may also be made electronically through CCC Online at copyright.com. Other copying for republication, resale, advertising or promotion, or any form of systematic or multiple reproduction of any material in this book is prohibited except with permission in writing from the publisher. The CCC fee code is 0277-786X/17/\$18.00.

Printed in the United States of America.

Publication of record for individual papers is online in the SPIE Digital Library.

\section{SPIE. DIGITAL \\ SPIEDigitalLibrary.org}

Paper Numbering: Proceedings of SPIE follow an e-First publication model. A unique citation identifier (CID) number is assigned to each article at the time of publication. Utilization of CIDs allows articles to be fully citable as soon as they are published online, and connects the same identifier to all online and print versions of the publication. SPIE uses a seven-digit CID article numbering system structured as follows:

- The first five digits correspond to the SPIE volume number.

- The last two digits indicate publication order within the volume using a Base 36 numbering system employing both numerals and letters. These two-number sets start with 00, 01, 02, 03, 04, 05, 06, 07, 08, 09, OA, OB ... 0Z, followed by 10-1Z, 20-2Z, etc. The CID Number appears on each page of the manuscript. 


\title{
Contents
}

\author{
vii Authors \\ ix Conference Committee \\ xi Introduction
}

\section{LIGHT SCATTERING}

1033002 Simulating propagation of coherent light in random media using the Fredholm type integral equation [10330-1]

1033004 Quantifying parameter uncertainties in optical scatterometry using Bayesian inversion [10330-3]

\section{OPTICAL SYSTEMS}

1033006 Combined use of a priori data for fast system self-calibration of a non-rigid multi-camera fringe projection system [10330-6]

1033007 Metrology and quality assurance for European XFEL long flat mirrors installation [10330-7]

1033009 Optical design of system for a lightship [10330-9]

\section{MUELLER POLARIMETRY}

10330 OA Experimental light scattering by small particles: first results with a novel Mueller matrix scatterometer [10330-10]

$10330 \mathrm{OB}$ B-spline parameterization of the dielectric function and information criteria: the craft of non-overfitting [10330-11]

\section{INTERFEROMETRY AND PHASE I}

10330 OD Phase retrieval with tunable phase transfer function based on the transport of intensity equation (Invited Paper) [10330-13]

$10330 \mathrm{OE}$ Experimental measurement and numerical analysis of group velocity dispersion in cladding modes of an endlessly single-mode photonic crystal fiber [10330-14]

10330 OF Study of the optical crosstalk in a heterodyne displacement gauge with cancelable circuit [10330-15] 
INTERFEROMETRY AND PHASE II

10330 OG Digital micromirror device as amplitude diffuser for multiple-plane phase retrieval [10330-17]

$10330 \mathrm{OH} \quad$ A flexible, simple telecentric three dimensional measurement system [10330-18]

10330 Ol Optofluidic in-plane Mach-Zehnder interferometer based on the liquid core/liquid cladding waveguides for refractive-Index measurements [10330-19]

\section{SCATTEROMETRY}

$10330 \mathrm{OJ} \quad$ Modeling surface imperfections in thin films and nanostructured surfaces (Invited Paper) [10330-20]

10330 OK In-line measuring method for periodical sub-wavelength nanostructures [10330-21]

\section{SURFACE TOPOGRAPHY AND FORM}

$10330 \mathrm{ON} \quad$ Numerical investigations of the potential for laser focus sensors in micrometrology (Invited Paper) [10330-25]

$1033000 \quad$ Measuring shape of a mirror with a moving camera [10330-26]

$103300 Q \quad$ Evaluation of a human corneal surface with the null-screen method [10330-28]

10330 OR Evaluation of the shape of a parabolic trough solar collector with flat null-screens [10330-29]

\section{GRATINGS: LER AND POLARISATION}

10330 OS Simulation of the influence of line edge roughness on the performance of deep ultraviolet wire grid polarizers (Invited Paper) [10330-30]

$10330 \mathrm{OU} \quad$ Fingerprinting the type of line edge roughness [10330-32]

\section{MICROSCOPY AND IMAGING}

10330 OV Role of coherence in microsphere-assisted nanoscopy (Invited Paper) [10330-33]

$10330 \mathrm{OW} \quad$ Optimizing image-based patterned defect inspection through FDTD simulations at multiple ultraviolet wavelengths (Invited Paper) [10330-34]

10330 OX Optical vortex microscope with the simple phase object: theoretical model and its experimental verification [10330-35] 
10330 OY Nanofabrication results of a novel cascaded plasmonic superlens: lessons learned [10330-36]

1033013 Simulation and considering in the experimental data of polarization effects in optical measuring instruments [10330-38]

1033014 Two-mirror device for laser scanning systems: multiparameter analysis [10330-39]

1033015 Measuring polarization dependent dispersion of non-polarizing beam splitter cubes with spectrally resolved white light interferometry [10330-40]

1033016 Numerical solution of deformation of circular membrane of liquid lens under uniform hydrostatic pressure [10330-41]

1033017 Development of graphene process control by industrial optical spectroscopy setup [10330-42]

1033018 Contact angle measurement by means of a confocal device [10330-43]

1033019 A tunable fiber optic LED illumination system for non-invasive measurements of the characteristics of a transparent fiber [10330-44]

10330 1A Hybrid model of arm for analysis of regional blood oxygenation in non-invasive optical diagnostics [10330-45]

10330 1B Modelling of influence of spherical aberration coefficients on depth of focus of optical systems [10330-46]

10330 1C A phase field study of stress effects on microstructure formation during laser-aided direct metal deposition process [10330-48]

10330 ID Analysis of instrumental effects on polarization of the polarimetric unit in the high-spectral resolution spectrograph with fiber input for the 6m SAO RAS telescope [10330-49]

10330 IE Characterization of a conical null-screen corneal topographer [10330-50]

10330 IF Assessment of yearly lidar ratio values in Penang, Malaysia [10330-51]

$103301 G$ Out-of-squareness measurement on ultra-precision machine based on the error separation [10330-52]

$10330 \mathrm{1H}$ Active marks structure optimization for optical-electronic systems of spatial position control of industrial objects [10330-53]

$103301 \mathrm{~J}$ Dielectric function parameterization by penalized splines [10330-55]

$103301 \mathrm{~K}$ Evaluation of thermal behavior during laser metal deposition using optical pyrometry and numerical simulation [10330-56] 
$10330 \mathrm{lL}$ Detection of nanoparticle changes in nanocomposite active sample using random laser emission [10330-57]

$103301 \mathrm{M}$ Modeling of nondestructive method for doped semiconductor layer diagnostics and experimental realization in a colloidal quantum dots [10330-58]

$103301 \mathrm{~N}$ Theoretical investigation on multilayer nanocomposite-based fiber optic SPR sensor [10330-59]

1033010 Application of the graphics processor unit to simulate a near field diffraction [10330-60]

$10330 \mathrm{lP}$ Comparison of interpolation and approximation methods for optical freeform synthesis [10330-61]

10330 IR Graphene based multimode interference coupler as an optical refractive index sensor based on nonlinear modal propagation analysis [10330-63]

10330 is Modeling on Bessel beam guide star beacon for wavefront sensing [10330-64]

10330 IT Phase retrieval technology within a single shot using multi-focal lengths chromatic aberration system [10330-65]

$103301 \mathrm{~V}$ Improvement of the method of optical testing of fast aspherical surfaces with null-screens [10330-67]

$10330 \mathrm{lW}$ Increase in the measurement of the normal vectors of an aspherical surface used in deflectometry [10330-68]

$103301 \mathrm{X}$ Interband and intraband optical light absorption in quantum dash systems [10330-69]

1033012 Errors in the estimation method for the rejection of vibrations in adaptive optics systems [10330-71]

1033020 Removing damped sinusoidal vibrations in adaptive optics systems using a DFT-based estimation method [10330-72] 


\section{Authors}

Numbers in the index correspond to the last two digits of the seven-digit citation identifier (CID) article numbering system used in Proceedings of SPIE. The first five digits reflect the volume number. Base 36 numbering is employed for the last two digits and indicates the order of articles within the volume. Numbers start with 00, 01, 02, 03, 04, 05, 06, 07, 08, 09, 0A, OB...0Z, followed by 10-1Z, 20-2Z, etc.

\author{
Abbasi, Shabnam, $1 \mathrm{~N}$ \\ Abregana, Timothy Joseph T., OG \\ Aguirre Aguirre, Daniel, $1 \mathrm{~V}$ \\ Alexe, Gabriela, OK \\ Almoro, Percival F., OG \\ Arasa, J., 18 \\ Armengol-Cruz, Victor de Emanuel, OQ, IV \\ Baghdasaryan, D. A., $1 \mathrm{X}$ \\ Bakholdin, A. V., ID \\ Barnes, Bryan M., OW \\ Baselt, Tobias, OE \\ Baver, J., 17 \\ Bischoff, Jörg, ON \\ Blanco, P., 18 \\ Bodermann, Bernd, 04 \\ Bointon, Patrick, 06 \\ Boriskin, A. G., $1 \mathrm{M}$ \\ Burger, Sven, 04 \\ Campos-García, Manuel, OQ, OR, 1E, IV \\ Castán-Ricaño, Diana, $1 \mathrm{~W}$ \\ Castilla, P., 18 \\ Chen, Shanyong, $1 \mathrm{G}$ \\ Chen, Shuxiao, 06 \\ Chen, Tong, $\mathrm{OH}$ \\ Chirkov, M. A., 09 \\ Cornejo-Rodríguez, A., IW \\ Cossio-Guerrero, Cesar, 0Q, 1E \\ Csonti, K., 15 \\ Díaz-Uribe, José Rufino, OR \\ Dickmann, Johannes, OS \\ Dneprovskii, V. S., $1 \mathrm{M}$ \\ Domínguez, N., 18 \\ Donazzan, Alberto, OF \\ Du, Shaojun, 1S, IT \\ Dubrov, Alexander V., $1 \mathrm{~K}$ \\ Dubrov, Vladimir D., $1 \mathrm{~K}$ \\ Duma, Maria-Alexandra, 14 \\ Duma, Virgil-Florin, 14 \\ Espínola, M., 18 \\ Fernández Herrero, A., OU \\ Fischer, Andreas, OK \\ Freijo Martín, Idoia, 07 \\ Frenner, Karsten, OY \\ Fu, Liwei, OY \\ Fursenko, O., 17 \\ Garcia Santiago, Xavier, 04 \\ García, C. 18 \\ Gharibzadeh, Azadeh, IN \\ Głomb, Grzegorz, 19
}

\author{
Granados-Agustín, Fermín S., IW \\ Gritsevich, Maria, OA \\ Guan, Chaoliang, IG \\ Haeggström, Edward, OA \\ Hammerschmidt, Martin, 04 \\ Hansen, P.-E., OJ \\ Hanyecz, V., 15 \\ Hartmann, Peter, OE \\ Hassim, M. A. A., $1 R$ \\ Helander, Petteri, OA \\ Henn, Mark-Alexander, OW \\ Hermosa, Nathaniel P., OG \\ Heusinger, Martin, OS \\ Horák, Martin, 16 \\ Hou, Xi, OP \\ Jensen, S. A., OJ \\ Jirásek, Milan, 16 \\ Kania, Dariusz, 1Z, 20 \\ Karamehmedovic, M., OJ \\ Kassamakov, Ivan, OA \\ Khor, Wei Ying, If \\ Korotaev, Valery $\mathrm{V}$., $1 \mathrm{H}$ \\ Kovács, A.P., 15 \\ Kozacki, T., OD \\ Kraszewski, Maciej, 02 \\ Krizskiy, Pavel, 1P \\ Kroker, Stefanie, OS \\ Kukushkin, D. E., 1D \\ Kulmon, Pavel, 16, 1B \\ Kurzynowski, Piotr, OX \\ Lai, Tao, $1 \mathrm{G}$ \\ Lasagni, Andrés Fabián, OE \\ Lashmanov, Oleg U., 1H \\ Latifi, Hamid, 0 I \\ Leach, Richard, 06 \\ Lecler, Sylvain, OV \\ Leong-Hoi, Audrey, OV \\ $\mathrm{Li}$, Dong, $\mathrm{OH}$ \\ Li, Huiyu, OY \\ Liao, Quan, $1 G$ \\ Likhachev, Dmitriy $\vee ., O B, 1 \mathrm{~J}$ \\ Lim, Hwee San, IF \\ Liu, Junfeng, $1 \mathrm{G}$ \\ Lukosius, M., 17 \\ Luo, Ruirao, 15 \\ Lupina, G., 17 \\ Maconi, Göran, OA \\ Madanipour, Khosro, 1L, 1N \\ Madsen, J. S., OJ
}


Madsen, M. H., OJ

Mai, A., 17

Manske, Eberhard, ON

Martinez-Carranza, J., OD

Masajada, Jan, OX

Mastylo, Rostyslav, ON

Mat Jafri, Mohamad Zubir, IF, IR

Mészáros, G., 15

Mikš, Antonín, 16, 1B

Mirzade, Fikret Kh., 1C, $1 \mathrm{~K}$

Montgomery, Paul C., OV

Mroczka, Janusz, 1A

Muinonen, Karri, OA

Muzychenko, Yana B., 10

Naletto, Giampiero, OF

Nelsen, Bryan, OE

Ning, $Y u, 1 S$

Novák, Jiří, 16, 1B

Novák, Pavel, 16, 1B

Nowocień, Sylwester, 1A

Oraie, Mohammadreza, 0

Osorio-Infante, Arturo I., IE

Osten, Wolfgang, OY

Pak, Alexey, 00

Pelizzo, Maria G., OF

Peña-Conzuelo, Andrés, OR

Penttilä, Antti, OA

Percino-Zacarías, E., IW

Perrin, Stephane, OV

Pflüger, M., OU

Piano, Samanta, 06

Pizarro, C., 18

Pluciński, Jerzy, 02

Pokorný, Petr, 16, 1B

Popiołek-Masajada, Agnieszka, OX

Puranen, Tuomas, OA

Quan, Haiyang, OP

Rojas Hurtado, Carol B., OS

Ryzhova, Victoria A., 13

Sazonenko, D. A., ID

Scholze, F., OU

Shojaie, Ehsan, 1L, 1N

Siefke, Thomas, OS

Silver, Richard M., OW

Sims-Waterhouse, Danny, 06

Sinn, Harald, 07

Šmejkal, Filip, 16, 1B

Smirnov, A. M., 1M

Sohn, Martin Y., OW

Soltwisch, $V .$, OU

Song, Weihong, OP

Southon, Nicholas, 06

Stavroulakis, Petros I., 06

Stepien, P., OD

Stöbener, Dirk, OK

Sun, Quan, 1S, $1 T$

Świrniak, Grzegorz, 19

Sycheva, Elena A., 1H

Tajaldini, M., IR

Taudt, Christopher, OE
Tausendfreund, Andreas, OK

Tian, Jindong, $\mathrm{OH}$

Tian, Yong, $\mathrm{OH}$

Tie, Guipeng, $1 \mathrm{G}$

Topalov, Oleg K., 10

Trushkina, Anna V., 13

Tsyganok, E. A., 09

Valyavin, G. G., ID

Vannoni, Maurizio, 07

Vasilev, Aleksandr S., 13, $1 \mathrm{H}$

Vasilyev, V. N., 1D

Villringer, C., 17

Voznesenskaya, Anna, IP

Weiser, Martin, 04

Wu, Fan, OP

$\mathrm{Wu}$, Jianmei, $\mathrm{OH}$

Wu, Wuming, is

Yang, Yi, 1S, IT

Zavalov, Yuri N., IK

Zhang, Xuanzhe, $1 \mathrm{~T}$

Zhou, Hui, OW

Zhou, Qiong, $1 T$

Zinchik, Alexander A., 10

Zschiedrich, Lin, 04 


\section{Conference Committee}

Symposium Chair

Wolfgang Osten, Universität Stuttgart (Germany)

Conference Chair

Bernd Bodermann, Physikalisch-Technische Bundesanstalt (Germany)

Conference Co-chairs

Karsten Frenner, Institut für Technische Optik (Germany)

Richard M. Silver, National Institute of Standards and Technology (United States)

Conference Program Committee

Markus Bär, Physikalisch-Technische Bundesanstalt (Germany)

Jörg Bischoff, Osires Optical Engineering (Germany)

Harald Bosse, Physikalisch-Technische Bundesanstalt (Germany)

Sven Burger, Konrad-Zuse-Zentrum für Informationstechnik (Germany)

Peter Evanschitzky, Fraunhofer-Institut für Integrierte Systeme und Bavelementetechnologie IISB (Germany)

Christian Hafner, ETH Zurich (Switzerland)

Wolfgang Holzapfel, Dr. Johannes Heidenhain GmbH (Germany)

Bernd H. Kleemann, Carl Zeiss AG (Germany)

Wolfgang Osten, Institut für Technische Optik (Germany)

Andreas Rathsfeld, Weierstrass-Institut für Angewandte Analysis und Stochastik (Germany)

Thomas Scherübl, Carl Zeiss SMS GmbH (Germany)

Patrick Schiavone, Aselta Nanographics (France)

Irwan D. Setija, ASML Netherlands B.V. (Netherlands)

Michael Totzeck, Carl Zeiss AG (Germany)

Jari Turunen, University of Eastern Finland (Finland)

Frank Wyrowski, Friedrich-Schiller-Universität Jena (Germany)

Session Chairs

1 Light Scattering

Stefanie Kroker, Physikalisch-Technische Bundesanstalt (Germany)

2 Optical Systems

Wolfgang Osten Universität Stuttgart (Germany) 
3 Mueller Polarimetry

Poul-Erik Hansen, Danish Fundamental Metrology (Denmark)

4 Interferometry and Phase I

Karsten Frenner, Institut für Technische Optik (Germany)

5 Interferometry and Phase II

Daniel Claus, Universität Stuttgart (Germany)

6 Scatterometry

Jörg Bischoff, Technische Universität Ilmenau (Germany)

7 Surface Topography and Form

Richard M. Silver, National Institute of Standards and Technology (United States)

8 Gratings: LER and Polarisation

Martin Hammerschmidt, Konrad-Zuse-Zentrum für Informationstechnik Germany)

9 Microscopy and Imaging

Bernd Bodermann, Physikalisch-Technische Bundesanstalt (Germany)

JS SPIE/OM/EQEC: Light and Structure

Timothy D. Drysdale, The Open University (United Kingdom) 


\section{Introduction}

The conference Modeling Aspects in Optical Metrology VI is organised as part of SPIE Optical Metrology Symposium, which is co-located with World of Photonics Congress 2017 in Munich, Germany. This conference is dedicated to establishling a forum to present and discuss the basic methods, techniques, and algorithms that are necessary for a proper modelling and simulation of applied optical metrology techniques. Special emphasis is placed on the description and modelling of new methods, algorithms, components or complete measurement systems.

Optical metrology methods are, in general, fast, non-destructive, reliable, flexible, and can nevertheless reach a high level of sensitivity. Therefore, their use in industrial applications such as process development or production control is continuously increasing. Concurrently, the metrological requirements are soaring rapidly, leading to a strong demand for both methodical extensions and improved metrology methods.

It is of utmost importance to fully understand the optical measurement process in order to exploit the full potential of optical metrology. This requires the ability of quantitatively predicting the dependence of the output of an optical sensor or measurement system on certain variations of the measurement object, the sensor itself, or the measurement environment. Only if these influences on the measurement result are well understood and appropriately considered in a suitable model of the measurement process, the measurement result and its associated measurement uncertainty can be used, for example, for reliable control of production processes. This in-depth understanding usually requires-or is at least strongly supported by-a reliable modelling or simulation of the optical measurement process. In this sense, modelling is a prerequisite for traceable and comparable measurements. This is particularly essential for recent and novel approaches in optical nanoscopy to bridge the gap between super-resolution imaging and real metrological applications.

Important topics are the development and verification of methods to describe the interaction of light with matter for quantitative characterization of micro- and nanostructures or the high accuracy description of light propagation in optical systems. Relevant applications range from optical metrology and inspection of nanostructures on masks and wafers in the semiconductor industry, display production, advanced photovoltaics, the investigation of grating structures and grating-based devices, the metrology of surfaces and layers to characterisation of complex optical systems. In many applications, nanometer or sub-nanometer measurement uncertainties are required. New and very interesting fields of application will arise in the physical and dimensional characterisation and the theoretical description of new and effective optical materials like photonic crystals or metamaterials. In combination with a better understanding and exploitation of novel nano-photonics and plasmonics, these developments will in the future 
enable a variety of novel optical components, systems and metrology systems with enhanced performance.

I would like to thank all contributors, participants, SPIE staff, the members of the program committee and the co-chairs for their support and for turning this conference into a success.

\section{Bernd Bodermann \\ Karsten Frenner Richard M. Silver}

